\title{
Interactive comment on "AEROCOM/AEROSAT AAOT SSA study, part I: evaluation and intercomparison of satellite measurements" by Nick Schutgens et al.
}

Nick Schutgens et al.

n.a.j.schutgens@vu.nl

Received and published: 27 January 2021

The comment was uploaded in the form of a supplement:

https://acp.copernicus.org/preprints/acp-2020-1207/acp-2020-1207-AC2-

supplement.pdf

Interactive comment on Atmos. Chem. Phys. Discuss., https://doi.org/10.5194/acp-2020-1207, 2020. 